\title{
Phase III Study of Cabozantinib in Previously Treated Metastatic Castration-Resistant Prostate Cancer: COMET-1
}

Matthew Smith, Johann De Bono, Cora Sternberg, Sylvestre Le Moulec, Stéphane Oudard, Ugo De Giorgi, Michael Krainer, Andries Bergman, Wolfgang Hoelzer, Ronald De Wit, Martin Bögemann, Fred Saad, Giorgio Cruciani, Antoine Thiery-Vuillemin, Susan Feyerabend, Kurt Miller, Nadine Houédé, Syed Hussain, Elaine Lam, Jonathan Polikoff, Arnulf Stenzl, Paul Mainwaring, David Ramies, Colin Hessel, Aaron Weitzman, and Karim Fizazi

See accompanying editorial on page 2958

Author affiliations appear at the end of this article.

Published online ahead of print at www.jco.org on July 11, 2016

Supported by Exelixis.

Presented in part at the 2015 Genitourinary Cancers Symposium Orlando, FL, February 26-28, 2015.

Authors' disclosures of potential conflicts of interest are found in the article online at www.jco.org. Author contributions are found at the end of this article.

Clinical trial information: NCT01605227.

Corresponding author: Matthew Smith, MD, PhD, Massachusetts General Hospital Cancer Center, Yawkey 7030, 55 Fruit St, Boston, MA 02114; e-mail: smith matthew@mgh.harvard.edu.

C 2016 by American Society of Clinical Oncology

0732-183X/16/3425w-3005w/\$20.00

DOI: 10.1200/JCO.2015.65.5597

\section{$\begin{array}{llllllll}\text { A } & \text { B } & \text { S } & \text { T } & \text { R } & \text { A } & \text { C } & \text { T }\end{array}$}

\section{Purpose}

Cabozantinib is an inhibitor of kinases, including MET and vascular endothelial growth factor receptors, and has shown activity in men with previously treated metastatic castration-resistant prostate cancer (mCRPC). This blinded phase III trial compared cabozantinib with prednisone in patients with mCRPC.

\section{Patients and Methods}

Men with progressive MCRPC after docetaxel and abiraterone and/or enzalutamide were randomly assigned at a two-to-one ratio to cabozantinib $60 \mathrm{mg}$ once per day or prednisone $5 \mathrm{mg}$ twice per day. The primary end point was overall survival (OS). Bone scan response (BSR) at week 12 as assessed by independent review committee was the secondary end point; radiographic progression-free survival (rPFS) and effects on circulating tumor cells (CTCs), bone biomarkers, serum prostatespecific antigen (PSA), and symptomatic skeletal events (SSEs) were exploratory assessments.

\section{Results}

A total of 1,028 patients were randomly assigned to cabozantinib ( $n=682$ ) or prednisone $(n=346)$. Median OS was 11.0 months with cabozantinib and 9.8 months with prednisone (hazard ratio, 0.90; $95 \% \mathrm{Cl}, 0.76$ to 1.06; stratified log-rank $P=.213$ ). BSR at week 12 favored cabozantinib ( $42 \% \vee 3 \%$; stratified Cochran-Mantel-Haenszel $P<.001)$. rPFS was improved in the cabozantinib group (median, 5.6 v 2.8 months; hazard ratio, $0.48 ; 95 \% \mathrm{Cl}, 0.40$ to 0.57 ; stratified log-rank $P<.001$ ). Cabozantinib was associated with improvements in CTC conversion, bone biomarkers, and post-random assignment incidence of SSEs but not PSA outcomes. Grade 3 to 4 adverse events and discontinuations because of adverse events were higher with cabozantinib than with prednisone $(71 \% \vee 56 \%$ and $33 \% \vee 12 \%$, respectively).

\section{Conclusion}

Cabozantinib did not significantly improve OS compared with prednisone in heavily treated patients with $\mathrm{MCRPC}$ and progressive disease after docetaxel and abiraterone and/or enzalutamide. Cabozantinib had some activity in improving BSR, rPFS, SSES, CTC conversions, and bone biomarkers but not PSA outcomes.

\section{J Clin Oncol 34:3005-3013. (C) 2016 by American Society of Clinical Oncology}

\section{INTRODUCTION}

Prostate cancer is a leading cause of cancer mortality in men worldwide. ${ }^{1}$ Nearly all prostate cancer-specific deaths occur after the development of metastatic castration-resistant prostate cancer (mCRPC). ${ }^{2}$ Approximately $90 \%$ of patients with mCRPC develop bone metastases, the predominant cause of morbidity in this population. $^{3-6}$
Docetaxel is standard first-line chemotherapy for mCRPC based on improvements in progressionfree (PFS) and overall survival (OS) compared with mitoxantrone plus prednisone. ${ }^{3,7,8}$ Two androgen pathway inhibitors, abiraterone acetate and enzalutamide, improved PFS and OS in patients with mCRPC when administered before ${ }^{9,10}$ or after chemotherapy. ${ }^{11,12}$ Significant OS benefit in patients with mCRPC has also been reported with sipuleucel-T, an autologous active cellular immunotherapy, radium-223, and cabazitaxel in 
combination with prednisone after progression during treatment with docetaxel. ${ }^{13-15}$ However, despite recent advances in clinical management, the prognosis for patients with mCRPC remains poor. $^{16,17}$

The receptor tyrosine kinase MET and the vascular endothelial growth factor (VEGF) signaling pathways seem to have important roles in prostate cancer development and progression. ${ }^{18}$ MET expression in prostate cancer was greater in bone metastases than in primary tumors and lymph node metastases. ${ }^{18-20}$ The VEGF pathway regulates cell proliferation, migration, differentiation, and survival through expression on osteoblasts and osteoclasts. Both MET and VEGF are thought to be involved in bone formation and remodeling. ${ }^{18-20}$

Cabozantinib is an orally bioavailable inhibitor of tyrosine kinases, including MET and VEGF receptor 2. Cabozantinib has shown activity in preclinical models of many tumor types, including prostate cancer. ${ }^{21-24}$ In a phase II, placebo-controlled, randomized discontinuation trial, cabozantinib demonstrated preliminary evidence of activity in multiple tumor types, including prostate $_{\text {cancer. }}{ }^{25}$ In patients with mCRPC, cabozantinib was associated with improvement in PFS (hazard ratio [HR], 0.12; $P<.001)$ and reductions in soft tissue lesions, bone turnover markers, pain, and narcotic use; the observed safety profile was consistent with other VEGF tyrosine kinase inhibitors (TKIs) ${ }^{25}$ In a subsequent nonrandomized expansion cohort of patients with mCRPC who had bone metastases and disease progression after docetaxel, cabozantinib (100 or $40 \mathrm{mg}$ per day) resulted in dramatic improvement in bone scans, pain, analgesic use, measurable soft tissue disease, circulating tumor cell (CTC) conversion, and bone biomarkers. ${ }^{26,27}$

On the basis of the promising clinical activity observed in patients with previously treated mCRPC, we conducted a phase III study of cabozantinib versus prednisone in men with MCRPC, bone metastases, and disease progression after docetaxel and abiraterone acetate and/or enzalutamide. The primary end point was OS, and bone scan response (BSR) at 12 weeks was the key secondary end point.

\section{PATIENTS AND METHODS}

\section{Patients}

The study enrolled patients age 18 years or older with MCRPC who had bone metastases and disease progression after docetaxel and abiraterone acetate and/or enzalutamide. There was no limit on the number of prior anticancer treatments. Eligible patients had documented histologic or cytologic diagnosis of adenocarcinoma of the prostate, serum testosterone levels lower than $1.75 \mathrm{nmol} / \mathrm{L}$, and evidence of bone metastases related to prostate cancer on bone scans from a protocol-credentialed scanner within 28 days before random assignment. Disease progression after prior therapy was defined as prostate-specific antigen (PSA) progression according to modified Prostate Cancer Working Group 2 criteria $^{28}$ or radiographic progression in soft tissue or bone lesions. Eligible patients had an Eastern Cooperative Oncology Group performance status (ECOG PS) of 0 to 2 and adequate organ and bone marrow function. Exclusion criteria are summarized in the Appendix (online only).

The study was approved by the institutional review board or ethics committee at each center and was conducted in accordance with Good Clinical Practice guidelines and the Declaration of Helsinki. An independent data monitoring committee monitored the study.

\section{Study Design}

This was a phase III, multicenter, randomized, double-blind controlled trial. Patients were randomly assigned at a two-to-one ratio to either cabozantinib or prednisone. Random assignment was stratified by prior cabazitaxel (yes $v$ no), baseline pain severity (worst pain by Brief Pain Inventory item 3 of $<4 v \geq 4$ ), and ECOG PS (0 to $1 v 2$ ). Random assignment and blinding procedures are summarized in the Appendix.

Cabozantinib was administered orally at $60 \mathrm{mg}$ once per day along with oral prednisone-matched placebo administered twice per day. Prednisone was administered orally at $5 \mathrm{mg}$ twice per day along with oral cabozantinib-matched placebo administered once per day. Patients continued study treatment as long as clinical benefit was experienced as determined by the investigator and as long as they did not experience unacceptable toxicity or meet other protocol-specified criteria. Patients were observed until death or until the sponsor's decision to no longer collect these data.

Dose reductions (from 60 to $40 \mathrm{mg}$ and 40 to $20 \mathrm{mg}$ ) or interruptions of cabozantinib or matched placebo treatment were allowed for unacceptable adverse events (AEs). Dose modification details are further summarized in the Appendix.

\section{End Points and Assessments}

The primary end point was OS. The secondary end point was BSR at week 12 , defined as a decrease of $30 \%$ or more in bone scan lesion area from baseline to week 12, which was evaluated by a central independent radiology review committee. ${ }^{29}$ Progressive disease on bone scan was defined as an increase of more than $30 \%$ from baseline in bone scan lesion area in areas attributable to metastatic disease or at least two new areas of radiotracer uptake attributable to metastatic disease in regions of bone not previously showing radiotracer uptake. Further information on BSR measurement and assessment is provided in the Appendix. Radiographic PFS (rPFS) was determined according to RECIST (version 1.1). ${ }^{30}$

Exploratory efficacy assessments included rPFS per investigator assessment, changes in CTCs, bone biomarkers, circulating PSA, and symptomatic skeletal events (SSEs). Exploratory end point assessments are summarized in the Appendix.

Safety assessments included monitoring of AEs and serious AEs (SAEs), deaths, standard laboratory test results, physical examination findings, and ECG recordings. Safety was assessed at least every 3 weeks up to week 12 (based on date of first dose) and every 6 weeks thereafter. AE terms were mapped to system organ class and preferred terms using the Medical Dictionary for Regulatory Activities (version 16.1). The seriousness, severity grade, and relationship of AEs to study treatment were assessed by the investigator, and severity grade was defined by the Common Terminology Criteria for Adverse Events (version 4.0).

\section{Statistical Methods and Analysis}

The study assumed a 7.0-month median OS for the control group based on the observed OS in the COU-AA-301 study. ${ }^{12}$ On the basis of a random assignment ratio of two to one of cabozantinib to prednisone, 578 deaths were required to provide $90 \%$ power to detect an HR of 0.75 (median OS, 7.0 months in prednisone group $v 9.3$ months in cabozantinib group) using the log-rank two-sided test at an overall type I error level of 0.05 .

The primary analysis of OS was conducted using the intent-to-treat population. The median duration of OS and the associated $95 \%$ CI for each treatment group were estimated using the Kaplan-Meier method. Inference testing was conducted using the log-rank test, stratified by the same factors used to stratify the random assignment. The HR and 95\% CI were estimated using a Cox proportional hazards model, with treatment group as the independent variable, and stratified by random assignment stratification factors. $P$ values are presented without control for multiple comparisons.

The percentage dose-intensity of cabozantinib was calculated as $100 \times($ average daily dose $[\mathrm{mg} /$ day $]) /(60 \mathrm{mg} /$ day $)$, and the percentage 


\begin{tabular}{|c|c|c|}
\hline \multirow[b]{2}{*}{ Characteristic } & \multicolumn{2}{|c|}{ No. (\%) } \\
\hline & $\begin{array}{c}\text { Cabozantinib } \\
(n=682)\end{array}$ & $\begin{array}{l}\text { Prednisone } \\
(n=346)\end{array}$ \\
\hline \multicolumn{3}{|l|}{ Age, years } \\
\hline Median & 69.5 & 69.0 \\
\hline Range & $35-87$ & $43-89$ \\
\hline \multicolumn{3}{|l|}{ Race } \\
\hline White & $520(76)$ & $265(77)$ \\
\hline Not reported & $140(21)$ & $71(21)$ \\
\hline Black or African American & $14(2)$ & $6(2)$ \\
\hline Asian & $2(0.3)$ & 0 \\
\hline $\begin{array}{l}\text { American Indian or Alaska } \\
\text { native }\end{array}$ & 0 & $1(0.3)$ \\
\hline Other & $6(0.9)$ & $3(0.9)$ \\
\hline \multicolumn{3}{|l|}{$\begin{array}{l}\text { Time from diagnosis to study } \\
\text { entry, years }\end{array}$} \\
\hline Median & 6.68 & 6.98 \\
\hline Range & $0.09-26.6$ & $0.04-22.2$ \\
\hline \multicolumn{3}{|l|}{ ECOG PS } \\
\hline 0 or 1 & $605(89)$ & $303(88)$ \\
\hline 2 & $76(11)$ & $43(12)$ \\
\hline Missing & $1(0.1)$ & 0 \\
\hline Gleason score $>7$ at diagnosis & $298(44)$ & $162(47)$ \\
\hline \multicolumn{3}{|l|}{ Bone scan lesion area, $\mathrm{mm}^{2}$} \\
\hline Median & $45,635.5$ & $41,746.0$ \\
\hline Range & $0-388,052$ & $0-283,304$ \\
\hline \multicolumn{3}{|l|}{ Extent of metastasis } \\
\hline None & 0 & 0 \\
\hline Bone & $681(100)$ & $346(100)$ \\
\hline \multicolumn{3}{|l|}{ Soft tissue } \\
\hline Lymph node & $313(46)$ & $140(40)$ \\
\hline Visceral & $133(20)$ & $58(17)$ \\
\hline Liver & $91(13)$ & $35(10)$ \\
\hline Lung & $69(10)$ & $29(8)$ \\
\hline Other soft tissue & $39(6)$ & $23(7)$ \\
\hline BPI worst pain $\geq 4$ & $284(42)$ & $148(43)$ \\
\hline $\begin{array}{l}\text { Opioid narcotic use within last } \\
24 \text { hours }\end{array}$ & $454(67)$ & $228(66)$ \\
\hline \multicolumn{3}{|l|}{ No. of prior anticancer agents* } \\
\hline 2 & 57 (8) & $31(9)$ \\
\hline$\geq 3$ & $625(92)$ & $315(91)$ \\
\hline \multicolumn{3}{|l|}{$\begin{array}{l}\text { Time from end of most recent } \\
\text { prior systemic anticancer } \\
\text { therapy to random } \\
\text { assignment, weeks }\end{array}$} \\
\hline Median & 4.71 & 4.14 \\
\hline Range & $-29.1-77.4$ & $0.7-66.9$ \\
\hline Received prior docetaxel & $682(100)$ & $346(100)$ \\
\hline \multicolumn{3}{|l|}{ Total cumulative dose, $\mathrm{mg} / \mathrm{m}^{2}$} \\
\hline Median & 615.0 & 613.0 \\
\hline Range & $140-5,625$ & $225-5,400$ \\
\hline \multicolumn{3}{|l|}{ Duration of treatment, months } \\
\hline Median & 5.68 & 5.73 \\
\hline Range & $0.95-59.10$ & $1.28-52.04$ \\
\hline Received prior abiraterone & $626(92)$ & $320(92)$ \\
\hline \multicolumn{3}{|l|}{ Duration of treatment, months } \\
\hline Median & 6.93 & 7.51 \\
\hline Range & $0.03-39.06$ & $0.10-62.59$ \\
\hline Received prior enzalutamide & $168(25)$ & $91(26)$ \\
\hline \multicolumn{3}{|l|}{ Duration of treatment, months } \\
\hline Median & 4.04 & 4.90 \\
\hline Range & $0.82-41.46$ & $0.07-34.53$ \\
\hline $\begin{array}{l}\text { Received prior docetaxel and } \\
\text { abiraterone and } \\
\text { enzalutamide }\end{array}$ & $112(16)$ & $66(19)$ \\
\hline $\begin{array}{r}\text { Prior radiation therapy for } \mathrm{CRPC}+ \\
\text { (continued }\end{array}$ & $\begin{array}{l}488(72) \\
x t \text { column) }\end{array}$ & $251(73)$ \\
\hline
\end{tabular}


$B S R$

BSR at week 12 per independent radiology review committee was $42 \%$ (95\% CI, 38\% to $46 \%$ ) with cabozantinib and 3\% (95\% CI, $1 \%$ to $5 \%$ ) with prednisone (unstratified and stratified Cochran-Mantel-Haenszel $P<.001$ for both; Table 2). For patients with a BSR $(\mathrm{n}=286)$, median duration of BSR (calculated from date of first BSR to date of bone scan progression) was 5.8 months (95\% CI, 5.5 to 8.3 ) with cabozantinib and 1.8 months (95\% CI, 0.62 to not estimable) with prednisone.

\section{PFS}

Cabozantinib was associated with improvements in investigatordetermined rPFS. Median rPFS was 5.6 months with cabozantinib and 2.8 months with prednisone (HR, 0.48; 95\% CI, 0.40 to 0.57 ; stratified log-rank $P<.001$; Fig $2 \mathrm{~B}$ ). Subsequent therapies received after progression were more common in the cabozantinib arm than in the prednisone arm (Table 3).

\section{Skeletal-Related Events}

Fifty-two percent of patients in the cabozantinib group and $54 \%$ of patients in the prednisone group had experienced one or more SSEs before study entry. Cabozantinib treatment was associated with an increase in time to first SSE (HR, 0.62; 95\% CI, 0.48 to 0.81 ; stratified $\log$-rank $P<.001$; Fig $2 \mathrm{C}$ ) and with lower rates of SSEs during study (cabozantinib, 14\%; prednisone, 21\%; Appendix Table A1, online only). Radiotherapy to bone was the most common SSE in both groups (cabozantinib, 12\%; prednisone, 18\%).

\section{CTCs, Bone Biomarkers, and PSA}

The favorable CTC conversion rate (defined as $\geq$ five CTCs at baseline to $<$ five CTCs as best postbaseline result) was 33\% for cabozantinib and $6 \%$ for prednisone (Appendix Table A2, online only). Cabozantinib treatment was also associated with improvement in bone-specific alkaline phosphatase, N-terminal cross-linked telopeptides of type I collagen, and C-terminal cross-linked telopeptides of type I collagen (Appendix Table A3, online only). Cabozantinib treatment was not associated with improved PSA response or time to PSA progression. A PSA response, defined as a reduction of $50 \%$ or more in PSA level, occurred in $6 \%$ of cabozantinib-treated patients and $2 \%$ of prednisone-treated patients. The median time to PSA progression was 4.2 and 3 months with cabozantinib and prednisone, respectively (unstratified $\mathrm{HR}, 0.95 ; P=.639$ ).

\section{Safety}

The median duration of study drug treatment was 20.1 weeks (range, 0.6 to 92.1 weeks) for cabozantinib and 12.3 weeks (range,

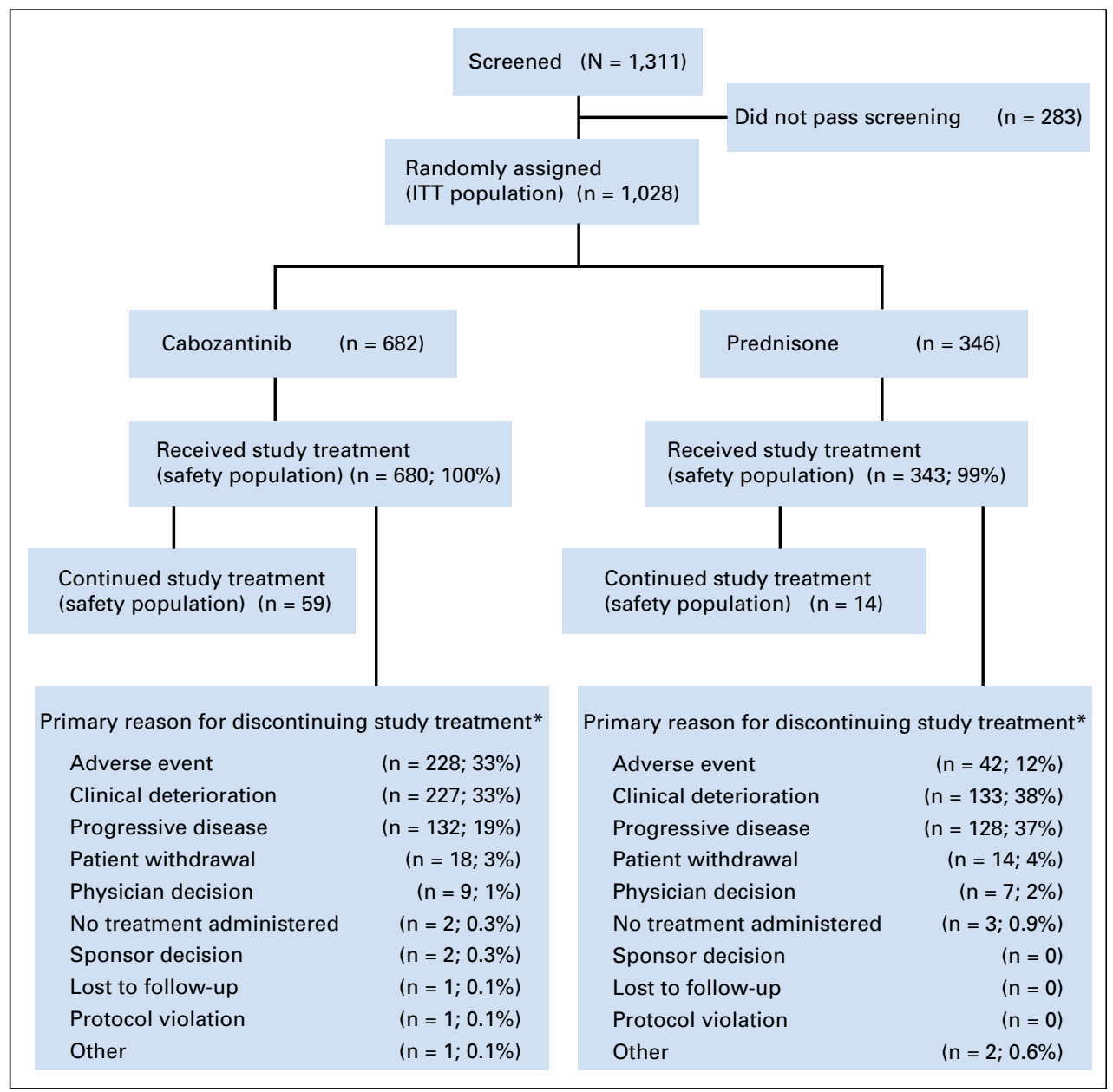

Fig 1. CONSORT diagram. ITT, intent to treat. (*) As of July 7, 2014. 


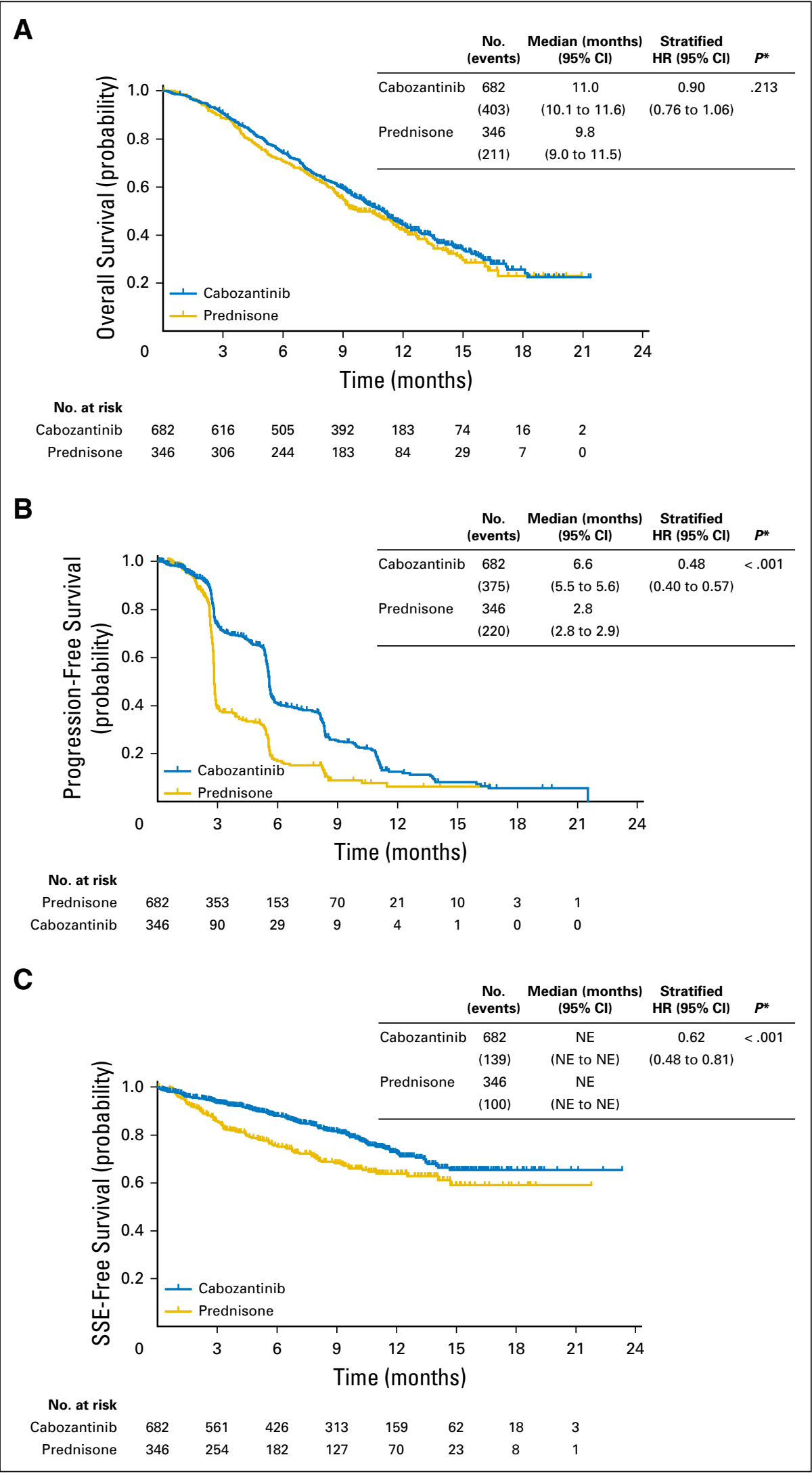

Fig 2. Kaplan-Meier plots of (A) overall survival, (B) radiographic progression-free survival, and (C) time to first symptomatic skeletal event (SSE). HR, hazard ratio; NE, not estimable. $\left(^{*}\right)$ Stratified logrank test. 


\begin{tabular}{|c|c|c|}
\hline \multirow[b]{2}{*}{ Response } & \multicolumn{2}{|c|}{ No. (\%) } \\
\hline & $\begin{array}{c}\text { Cabozantinib } \\
(n=682)\end{array}$ & $\begin{array}{l}\text { Prednisone } \\
(n=346)\end{array}$ \\
\hline \multicolumn{3}{|l|}{ Best overall response } \\
\hline Responder & $288(42)$ & 9 (3) \\
\hline Stable bone scan & $136(20)$ & $102(29)$ \\
\hline $\begin{array}{l}\text { Progressive bone } \\
\text { scan }\end{array}$ & $66(10)$ & 129 (37) \\
\hline Unable to evaluate & 0 & 0 \\
\hline Missing* & $192(28)$ & $106(31)$ \\
\hline BSR at week 12 & $288(42)$ & $9(3)$ \\
\hline $95 \% \mathrm{Cl}$ & $38 \%$ to $46 \%$ & $1 \%$ to $5 \%$ \\
\hline Stratified $\mathrm{CMH} P \dagger$ & \multicolumn{2}{|c|}{$<.001$} \\
\hline Unstratified $\mathrm{CMH} P \dagger$ & \multicolumn{2}{|c|}{$<.001$} \\
\hline \multicolumn{3}{|c|}{$\begin{array}{l}\text { Abbreviations: BSR, bone scan response; CMH, Cochran-Mantel-Haenszel; } \\
\text { IRC, independent radiology review committee. } \\
\text { *Indicates no qualifying baseline or postbaseline assessment. } \\
+P \text { value was obtained using the } \mathrm{CMH} \text { test (adjusted for stratification factors, if } \\
\text { applicable). }\end{array}$} \\
\hline
\end{tabular}

2.0 to 71.1 weeks) for prednisone. The median percentage doseintensity was $75 \%$ for cabozantinib and $100 \%$ for prednisone.

The most common AEs in both groups are listed in Table 4. SAEs were reported by $62 \%$ and $53 \%$ of patients in the cabozantinib and prednisone groups, respectively. The following SAEs occurred at an incidence of at least $2 \%$ higher with cabozantinib compared with prednisone: pulmonary embolism $(6.2 \% v 0.9 \%)$, vomiting $(4.1 \% \vee 1.8 \%)$, fatigue $(2.9 \% \vee 0.9 \%)$, and dehydration (2.9\% $v 0.3 \%)$.

Study drug discontinuations because of AEs were reported for $33 \%$ and $12 \%$ of patients in the cabozantinib and prednisone groups, respectively (Appendix Table A4, online only). AEs leading to dose reductions or interruptions were reported for $88 \%$ and $45 \%$ of patients in the cabozantinib and prednisone groups, respectively, and AEs that led to dose reductions were reported for $67 \%$ and $15 \%$ of patients, respectively. The median time to first dose level reduction was 47.5 days (range, 6 to 379 days) and 44 days (range, 22 to 344 days) in the

Table 3. Concomitant and Subsequent Nonprotocol Anticancer Therapy Received

\begin{tabular}{lcc}
\hline & \multicolumn{2}{c}{ No. (\%) } \\
\cline { 2 - 3 } \multicolumn{1}{c}{ Therapy } & $\begin{array}{c}\text { Cabozantinib } \\
\text { (n = 682) }\end{array}$ & $\begin{array}{c}\text { Prednisone } \\
\text { (n = 346) }\end{array}$ \\
\hline Any anticancer therapy & $374(55)$ & $236(68)$ \\
Systemic nonirradiation anticancer therapy & $258(38)$ & $175(51)$ \\
Local nonirradiation therapy & $28(4)$ & $10(3)$ \\
Any radiation therapy (including & $176(26)$ & $116(34)$ \\
$\quad$ radionuclides) & $373(55)$ & $236(68)$ \\
Any medications* & $95(14)$ & $78(23)$ \\
Cabazitaxel* & $137(20)$ & $75(22)$ \\
Enzalutamide* & $84(12)$ & $69(20)$ \\
External-beam radiation therapy* & $17(2.5)$ & $30(8.7)$ \\
Docetaxel* & $37(5.4)$ & $26(7.5)$ \\
Abiraterone acetate* & $42(6.2)$ & $19(5.5)$ \\
Radium-223 chloride/alpharadin* & & \\
\hline
\end{tabular}

*With $\geq 5 \%$ incidence in any treatment arm. cabozantinib and prednisone groups, respectively. AEs leading to dose modifications are summarized in Appendix Table A5 (online only).

Grade 5 AEs occurring within 30 days of the last study drug dose were reported in $15 \%$ and $13 \%$ of patients in the cabozantinib and prednisone groups, respectively, and were most commonly considered disease related. Deaths considered not related to prostate cancer and occurring within 30 days of the last study dose are summarized in the Appendix.

\section{DISCUSSION}

In this randomized, controlled trial of men with mCRPC and bone metastases with disease progression after docetaxel and abiraterone acetate and/or enzalutamide, cabozantinib did not significantly improve OS compared with prednisone. Consistent with observations from phase II studies, ${ }^{25,26}$ cabozantinib was associated with improvements in other study outcomes, including BSR, rPFS, SSEs, CTCs, and bone biomarkers, but not PSA outcomes.

The primary results of this study are consistent with the published results of sunitinib, an orally available TKI that inhibits VEGF receptor 2 but not MET. In phase II studies of patients with mCRPC, sunitinib was observed to have modest effects on bone scans and bone biomarkers. ${ }^{31}$ In a phase III randomized controlled trial of patients with mCRPC and disease progression after docetaxel, sunitinib did not improve OS compared with placebo (HR, $0.914 ; 95 \% \mathrm{CI}, 0.762$ to 1.097 ; $P=.168){ }^{32}$ Sunitinib was associated with significant improvement in PFS (HR, 0.725; 95\% CI, 0.591 to $0.890 ; P<.001$ ) and higher rates of study drug discontinuation because of AEs (27\% v 7\%) compared with placebo. The phase III sunitinib study did not report effects on bone scans, CTCs, or bone biomarkers. Other compounds targeting VEGF and angiogenesis, such as bevacizumab, afilbercept, and lenalidomide, have also failed to improve OS in patients with MCRPC when combined with docetaxel. ${ }^{33-35}$ No significant anticancer activity was detected with the MET-targeting agent rilotumumab when combined with mitoxantrone. ${ }^{36}$

In metastatic prostate cancer, CTC counts at baseline have prognostic value, and changes during therapy have been considered predictive of treatment benefit. ${ }^{37-39}$ Furthermore, higher CTC counts have been observed in patients with bone metastases compared with those without bone metastases. ${ }^{37,40}$ In our study, a higher incidence of CTC conversion, from five or more cells at baseline (indicative of unfavorable prognosis) to fewer than five cells postbaseline (indicative of favorable prognosis), in the cabozantinib group compared with the prednisone group was observed. These findings, along with favorable changes in other biomarkers, except PSA, support the hypothesis that cabozantinib treatment was associated with biologic activity affecting both tumor cells and the bone microenvironment.

The biologic activities of cabozantinib are diverse, with bone effects, direct effects on cancer cells, and antiangiogenic effects being demonstrated in preclinical models. ${ }^{21-23}$ It could be argued that the observed changes in BSR, bone biomarkers, 
Table 4. Summary of Frequently-Reported AEs Occurring in $\geq 10 \%$ of Patients in Either Treatment Group

\begin{tabular}{|c|c|c|c|c|}
\hline \multirow[b]{3}{*}{$\mathrm{AE}$} & \multicolumn{4}{|c|}{ No. (\%) } \\
\hline & \multicolumn{2}{|c|}{$\begin{array}{c}\text { Cabozantinib } \\
(n=681)\end{array}$} & \multicolumn{2}{|c|}{$\begin{array}{l}\text { Prednisone } \\
(\mathrm{n}=342)\end{array}$} \\
\hline & All Grades & Grades 3 to 4 & All Grades & Grades 3 to 4 \\
\hline Patients with one or more $\mathrm{AE}$ & $680(100)$ & $481(71)$ & $333(97)$ & $191(56)$ \\
\hline Decreased appetite & $411(60)$ & $55(8.1)$ & $100(29)$ & $7(2.0)$ \\
\hline Nausea & $394(58)$ & $47(6.9)$ & $106(31)$ & $7(2.0)$ \\
\hline Diarrhea & $353(52)$ & $50(7.3)$ & $70(20)$ & $5(1.5)$ \\
\hline Fatigue & $347(51)$ & $119(17)$ & $120(35)$ & $30(8.8)$ \\
\hline Vomiting & $278(41)$ & $38(5.6)$ & $70(20)$ & $8(2.3)$ \\
\hline Asthenia & $238(35)$ & $84(12)$ & $64(19)$ & $21(6.1)$ \\
\hline Weight decreased & $237(35)$ & $23(3.4)$ & $41(12)$ & $2(0.6)$ \\
\hline Constipation & $232(34)$ & $7(1.0)$ & $104(30)$ & $3(0.9)$ \\
\hline Anemia & $208(31)$ & $108(16)$ & $113(33)$ & $61(18)$ \\
\hline PPE syndrome & $200(29)$ & $39(5.7)$ & $5(1.5)$ & 0 \\
\hline Hypertension & $195(29)$ & $135(20)$ & $39(11)$ & $24(7.0)$ \\
\hline Dysphonia & $182(27)$ & 0 & $21(6.1)$ & 0 \\
\hline Dysgeusia & $175(26)$ & $1(0.1)$ & $16(4.7)$ & 0 \\
\hline Dyspnea & $141(21)$ & $24(3.5)$ & 49 (14) & $4(1.2)$ \\
\hline Mucosal inflammation & $137(20)$ & $22(3.2)$ & $9(2.6)$ & 0 \\
\hline Stomatitis & 127 (19) & $18(2.6)$ & $8(2.3)$ & 0 \\
\hline Back pain & $122(18)$ & $29(4.3)$ & $67(20)$ & $13(3.8)$ \\
\hline Bone pain & $118(17)$ & $35(5.1)$ & $68(20)$ & $23(6.7)$ \\
\hline Edema peripheral & $102(15)$ & $5(0.7)$ & $44(13)$ & $3(0.9)$ \\
\hline Pain in extremity & $102(15)$ & $18(2.6)$ & $37(11)$ & $3(0.9)$ \\
\hline Arthralgia & $94(14)$ & $16(2.3)$ & $53(15)$ & $9(2.6)$ \\
\hline Hypothyroidism & $94(14)$ & 0 & $1(0.3)$ & 0 \\
\hline General physical health deterioration & $90(13)$ & $53(7.8)$ & $32(9.4)$ & $20(5.8)$ \\
\hline Headache & $88(13)$ & $3(0.4)$ & $17(5.0)$ & $3(0.9)$ \\
\hline Abdominal pain & $80(12)$ & $13(1.9)$ & $19(5.6)$ & $6(1.8)$ \\
\hline Urinary tract infection & $79(12)$ & $15(2.2)$ & $33(9.6)$ & $7(2.0)$ \\
\hline Pyrexia & $78(11)$ & $4(0.6)$ & $39(11)$ & $2(0.6)$ \\
\hline Aspartate aminotransferase & $71(10)$ & $14(2.1)$ & $14(4.1)$ & $4(1.2)$ \\
\hline Hypokalemia & $71(10)$ & $26(3.8)$ & $9(2.6)$ & $2(0.6)$ \\
\hline Pain & $62(9.1)$ & $18(2.6)$ & $38(11)$ & $19(5.6)$ \\
\hline Musculoskeletal pain & $46(6.8)$ & $7(1.0)$ & $37(11)$ & $3(0.9)$ \\
\hline
\end{tabular}

Abbreviations: $A E$, adverse event; PPE, palmar-plantar erythrodysesthesia

and SSEs in our study are consistent with biologic effects in bone and bone metastases, and the improvements in CTCs suggest a direct antitumor effect, although the lack of improvement in PSA outcomes argues against such an effect. On the basis of phase II study results, it was clear that the effects of cabozantinib on intermediate end points were complex and in some cases contradictory. For these reasons, OS was selected as the primary study end point.

The cabozantinib dose selected in this trial was based on findings from a phase II expansion cohort in patients with mCRPC who received either 100 or $40 \mathrm{mg}$ of cabozantinib per day. ${ }^{27}$ Both doses showed activity in late-stage mCRPC, with improved tolerability at the 40-mg dose. In another study, the 40-mg dose showed substantial pharmacodynamic activity for BSR, whereas activity seemed markedly attenuated at a 20 -mg dose. ${ }^{41}$ Therefore, a dose of $60 \mathrm{mg}$ per day was selected for phase III investigation in $\mathrm{MCRPC}$ as an active dose that could be reduced to $40 \mathrm{mg}$ for tolerability while still maintaining pharmacodynamic activity.

Safety data in this trial were consistent with those observed in earlier-stage cabozantinib trials in $\mathrm{mCRPC},{ }^{25,27}$ and no new or unexpected AEs occurred. Adverse effects typically associated with VEGF inhibition and/or TKI use, such as hypertension, fatigue, and palmar-plantar erythrodysesthesia syndrome, were observed at higher rates with cabozantinib compared with prednisone. The pulmonary embolism incidence with cabozantinib was consistent with that previously described in phase II trials in patients with mCRPC treated with agents targeting the VEGF pathway. ${ }^{25,27}$ Dehydration was also observed in this population, and this may have been associated with the higher incidence of GI disorders (eg, diarrhea, nausea, and vomiting) with cabozantinib treatment. Sixty-seven percent of patients had AEs that led to dose reductions, a rate lower than that observed in a phase III trial of a higher dose of cabozantinib (140 mg/day) in patients with metastatic medullary thyroid cancer, whereas the rate of treatment discontinuation because of AEs with cabozantinib was substantially higher in our study $(33 \% v 16 \%){ }^{42}$ These results indicate insufficient tolerability of the 60-mg dose of cabozantinib in our older patient population with heavily pretreated mCRPC, and lower doses and/or more proactive management of AEs should be considered in future investigations.

It is unclear why improvements in BSR, rPFS, SSEs, CTC conversions, and bone biomarkers with cabozantinib did not translate into significantly improved OS in this population of patients with late-stage mCRPC. Notably, the relationship between intermediate outcomes and OS may vary from drug to 
drug. Alternatively, the lack of a significant OS benefit despite improvements in a variety of other intermediate outcomes may have resulted from high rates of treatment discontinuation because of AEs, confounding effects of subsequent salvage therapies, the use of an active comparator, unidentified imbalances in prognostic factors between treatment arms, and/or limitations of intermediate end points for assessment of certain targeted therapies.

MET overexpression has been shown to be more common in metastatic sites compared with primary prostate cancer samples. ${ }^{43}$ Aberrant expression of hepatocyte growth factor, the MET ligand, has also been shown to promote tumor progression in preclinical studies, and high plasma levels of hepatocyte growth factor have been correlated with poor outcomes in patients with prostate cancer. ${ }^{44,45}$ The successful development of cabozantinib in mCRPC may require a specific biomarker evaluation to identify patients with a high likelihood of treatment benefit.

In summary, cabozantinib did not significantly improve OS in patients with mCRPC and disease progression after docetaxel and abiraterone acetate and/or enzalutamide. Cabozantinib was not associated with improvements in PSA outcomes. However, improvements in other study outcomes, including BSR, rPFS, time to first SSE, CTC conversions, and bone biomarkers, are notable.
AUTHORS' DISCLOSURES OF POTENTIAL CONFLICTS OF INTEREST

Disclosures provided by the authors are available with this article at www.jco.org.

\section{AUTHOR CONTRIBUTIONS}

Conception and design: Matthew Smith, Johann De Bono, Cora Sternberg, Ronald De Wit, David Ramies, Colin Hessel, Aaron Weitzman, Karim Fizazi Provision of study materials or patients: Matthew Smith, Johann De Bono, Sylvestre Le Moulec, Ronald De Wit, Fred Saad, Nadine Houédé, Elaine Lam, Karim Fizazi

Collection and assembly of data: Matthew Smith, Johann De Bono, Sylvestre Le Moulec, Stéphane Oudard, Ugo De Giorgi, Michael Krainer, Andries Bergman, Wolfgang Hoelzer, Ronald De Wit, Martin Bögemann, Fred Saad, Giorgio Cruciani, Antoine Thiery-Vuillemin, Susan Feyerabend, Kurt Miller, Nadine Houédé, Syed Hussain, Elaine Lam, Jonathan Polikoff, Arnulf Stenzl, Paul Mainwaring, David Ramies, Colin Hessel, Aaron Weitzman, Karim Fizazi

Data analysis and interpretation: Matthew Smith, Johann De Bono, Stéphane Oudard, Ronald De Wit, Fred Saad, Antoine Thiery-Vuillemin, Paul Mainwaring, David Ramies, Colin Hessel, Aaron Weitzman, Karim Fizazi

Manuscript writing: All authors

Final approval of manuscript: All authors

\section{REFERENCES}

1. Torre LA, Bray F, Siegel RL, et al: Global cance statistics, 2012. CA Cancer J Clin 65:87-108, 2015

2. Halabi $S$, Vogelzang $N J$, Kornblith $A B$, et al: Pain predicts overall survival in men with metastatic castration-refractory prostate cancer. J Clin Oncol 26 2544-2549, 2008

3. Tannock IF, de Wit R, Berry WR, et al: Docetaxel plus prednisone or mitoxantrone plus prednisone for advanced prostate cancer. N Engl J Med 351:1502-1512, 2004

4. El-Amm J, Aragon-Ching JB: The changing landscape in the treatment of metastatic castrationresistant prostate cancer. Ther Adv Med Oncol 5: 25-40, 2013

5. Bubendorf L, Schöpfer A, Wagner $U$, et al: Metastatic patterns of prostate cancer: An autopsy study of 1,589 patients. Hum Pathol 31:578-583, 2000

6. Costa L, Badia X, Chow E, et al: Impact of skeletal complications on patients' quality of life, mobility, and functional independence. Support Care Cancer 16:879-889, 2008

7. Berthold DR, Pond GR, Soban F, et al: Docetaxel plus prednisone or mitoxantrone plus prednisone for advanced prostate cancer: Updated survival in the TAX 327 study. J Clin Oncol 26:242-245, 2008

8. Petrylak DP, Tangen $\mathrm{CM}$, Hussain $\mathrm{MH}$, et al: Docetaxel and estramustine compared with mitoxantrone and prednisone for advanced refractory prostate cancer. N Engl J Med 351:1513-1520, 2004

9. Beer TM, Armstrong AJ, Rathkopf DE, et al: Enzalutamide in metastatic prostate cancer before chemotherapy. N Engl J Med 371:424-433, 2014

10. Ryan CJ, Smith MR, Fizazi K, et al: Abiraterone acetate plus prednisone versus placebo plus prednisone in chemotherapy-naive men with metastatic castration-resistant prostate cancer (COU-AA-302): Final overall survival analysis of a randomised, double-blind, placebo-controlled phase 3 study. Lancet Oncol 16:152-160, 2015

11. Scher HI, Fizazi K, Saad F, et al: Increased survival with enzalutamide in prostate cancer after chemotherapy. N Engl J Med 367:1187-1197, 2012

12. de Bono JS, Logothetis CJ, Molina A, et al: Abiraterone and increased survival in metastatic prostate cancer. N Engl J Med 364:1995-2005, 2011

13. Kantoff PW, Higano CS, Shore ND, et al: Sipuleucel-T immunotherapy for castration-resistant prostate cancer. N Engl J Med 363:411-422, 2010

14. de Bono JS, Oudard S, Ozguroglu M, et al: Prednisone plus cabazitaxel or mitoxantrone for metastatic castration-resistant prostate cancer progressing after docetaxel treatment: A randomised open-label trial. Lancet 376:1147-1154, 2010

15. Parker C, Nilsson $S$, Heinrich D, et al: Alpha emitter radium-223 and survival in metastatic prostate cancer. N Engl J Med 369:213-223, 2013

16. Gillessen $S$, Omlin A, Attard G, et al: Management of patients with advanced prostate cancer: Recommendations of the St Gallen Advanced Prostate Cancer Consensus Conference (APCCC) 2015 Ann Oncol 26:1589-1604, 2015

17. Horwich A, Hugosson J, de Reijke $T$, et al: Prostate cancer: ESMO Consensus Conference Guidelines 2012. Ann Oncol 24:1141-1162, 2013

18. Aftab DT, McDonald DM: MET and VEGF: Synergistic targets in castration-resistant prostate cancer. Clin Transl Oncol 13:703-709, 2011

19. Zhang $\mathrm{S}$, Zhau HE, Osunkoya $A O$, et al: Vascular endothelial growth factor regulates myeloid cell leukemia-1 expression through neuropilin-1. dependent activation of c-MET signaling in human prostate cancer cells. Mol Cancer 9:9, 2010

20. Knudsen BS, Gmyrek GA, Inra J, et al: High expression of the Met receptor in prostate cancer metastasis to bone. Urology 60:1113-1117, 2002
21. Dai J, Zhang $H$, Karatsinides $A$, et al: Cabozantinib inhibits prostate cancer growth and prevents tumor-induced bone lesions. Clin Cancer Res 20: 617-630, 2014

22. Nguyen HM, Ruppender $N$, Zhang $X$, et al: Cabozantinib inhibits growth of androgen-sensitive and castration-resistant prostate cancer and affects bone remodeling. PLoS One 8:e78881, 2013 [Erratum PLoS One 9:e106797, 2014]

23. Yakes FM, Chen J, Tan J, et al: Cabozantinib (XL184), a novel MET and VEGFR2 inhibitor, simultaneously suppresses metastasis, angiogenesis, and tumor growth. Mol Cancer Ther 10:2298-2308, 2011

24. Graham TJ, Box G, Tunariu N, et al: Preclinical evaluation of imaging biomarkers for prostate cance bone metastasis and response to cabozantinib. J Nat Cancer Inst 106:dju033, 2014

25. Smith DC, Smith MR, Sweeney C, et al: Cabozantinib in patients with advanced prostate cancer: Results of a phase II randomized discontinuation trial. J Clin Oncol 31:412-419, 2013

26. Basch $E$, Autio KA, Smith MR, et al: Effects of cabozantinib on pain and narcotic use in patients with castration-resistant prostate cancer: Results from a phase 2 nonrandomized expansion cohort. Eur Urol 67:310-318, 2015

27. Smith MR, Sweeney CJ, Corn PG, et al: Cabozantinib in chemotherapy-pretreated metastatic castration-resistant prostate cancer: Results of a phase II nonrandomized expansion study. J Clin Oncol 32:3391-3399, 2014

28. Scher HI, Halabi S, Tannock I, et al: Design and end points of clinical trials for patients with progressive prostate cancer and castrate levels of testosterone: Recommendations of the Prostate Cancer Clinical Trials Working Group. J Clin Oncol 26: 1148-1159, 2008

29. Brown MS, Chu GH, Kim HJ, et al: Computeraided quantitative bone scan assessment of prostate 
cancer treatment response. Nucl Med Commun 33: 384-394, 2012

30. Eisenhauer EA, Therasse $P$, Bogaerts J, et al: New response evaluation criteria in solid tumours: Revised RECIST guideline (version 1.1). Eur J Cancer 45:228-247, 2009

31. Saylor PJ, Mahmood U, Kunawudhi A, et al: Multitargeted tyrosine kinase inhibition produces discordant changes between ${ }^{99 \mathrm{~m}}$ Tc-MDP bone scans and other disease biomarkers: Analysis of a phase II study of sunitinib for metastatic castration-resistant prostate cancer. J Nucl Med 53:1670-1675, 2012

32. Michaelson MD, Oudard S, Ou YC, et al: Randomized, placebo-controlled, phase III trial of sunitinib plus prednisone versus prednisone alone in progressive, metastatic, castration-resistant prostate cancer. J Clin Oncol 32:76-82, 2014

33. Tannock IF, Fizazi K, Ivanov S, et al: Aflibercept versus placebo in combination with docetaxel and prednisone for treatment of men with metastatic castration-resistant prostate cancer (VENICE): A phase 3, double-blind randomised trial. Lancet Oncol 14:760-768, 2013

34. Kelly WK, Halabi S, Carducci M, et al: Randomized, double-blind, placebo-controlled phase III trial comparing docetaxel and prednisone with or without bevacizumab in men with metastatic castrationresistant prostate cancer: CALGB 90401. J Clin Oncol 30:1534-1540, 2012

35. Petrylak DP, Vogelzang NJ, Budnik N, et al: Docetaxel and prednisone with or without lenalidomide in chemotherapy-naive patients with metastatic castration-resistant prostate cancer (MAINSAIL): A randomised, double-blind, placebocontrolled phase 3 trial. Lancet Oncol 16:417-425, 2015

36. Ryan CJ, Rosenthal M, Ng S, et al: Targeted MET inhibition in castration-resistant prostate cancer: A randomized phase II study and biomarker analysis with rilotumumab plus mitoxantrone and prednisone. Clin Cancer Res 19:215-224, 2013

37. Olmos D, Arkenau HT, Ang JE, et al: Circulating tumour cell (CTC) counts as intermediate end points in castration-resistant prostate cancer (CRPC): A single-centre experience. Ann Oncol 20:27-33, 2009

38. Scher HI, Morris MJ, Larson S, et al: Validation and clinical utility of prostate cancer biomarkers. Nat Rev Clin Oncol 10:225-234, 2013

39. de Bono JS, Scher HI, Montgomery RB, et al: Circulating tumor cells predict survival benefit from treatment in metastatic castration-resistant prostate cancer. Clin Cancer Res 14:6302-6309, 2008

40. Danila DC, Heller G, Gignac GA, et al: Circulating tumor cell number and prognosis in progressive castration-resistant prostate cancer. Clin Cancer Res 13:7053-7058, 2007

41. Lee RJ, Saylor PJ, Michaelson MD, et al: A dose-ranging study of cabozantinib in men with castration-resistant prostate cancer and bone metastases. Clin Cancer Res 19:3088-3094, 2013

42. Elisei $R$, Schlumberger MJ, Müller SP, et al: Cabozantinib in progressive medullary thyroid cancer. $\mathrm{J}$ Clin Oncol 31:3639-3646, 2013

43. Humphrey PA, Zhu $X$, Zarnegar $R$, et al: Hepatocyte growth factor and its receptor (c-MET) in prostatic carcinoma. Am J Pathol 147:386-396, 1995

44. Gupta A, Karakiewicz PI, Roehrborn CG, et al: Predictive value of plasma hepatocyte growth factor/ scatter factor levels in patients with clinically localized prostate cancer. Clin Cancer Res 14:7385-7390, 2008

45. Hurle RA, Davies G, Parr C, et al: Hepatocyte growth factor/scatter factor and prostate cancer: A review. Histol Histopathol 20:1339-1349, 2005

\section{Affiliations}

Matthew Smith, Massachusetts General Hospital, Boston, MA; Johann De Bono, Royal Marsden Hospital, Sutton; Syed Hussain, University of Liverpool, Liverpool, United Kingdom; Cora Sternberg, San Camillo and Forlanini Hospitals, Rome; Ugo De Giorgi, Istituto Scientifico Romagnolo per lo Studio e la Cura dei Tumori-Istituto di Ricovero e Cura a Carattere Scientifico, Meldola; Giorgio Cruciani, Istituto Tumori Romagna, Lugo di Romagna, Italy; Sylvestre Le Moulec, Hôpital d'Instruction des Armées Val-de-Grâce; Stéphane Oudard, European Hospital Georges Pompidou and Paris Descartes University, Paris; Antoine Thiery-Vuillemin, Jean Minjoz Hospital, Besançon; Nadine Houédé, Institut de Cancérologie du Gard-Centre Hospitalier Universitaire Caremeau, Nîmes; Karim Fizazi, Institute Gustave Roussy, University of Paris Sud, Villejuif, France; Michael Krainer, Medical University of Vienna, Vienna, Austria; Andries Bergman, Netherlands Cancer Institute, Amsterdam; Ronald De Wit, Erasmus University Medical Center and Cancer Institute, Rotterdam, the Netherlands; Wolfgang Hoelzer, Praxis für Urologie; Kurt Miller, Charité-Universitätsmedizin Berlin, Berlin; Martin Bögemann, University of Muenster Medical Center, Muenster; Susan Feyerabend, Studienpraxis Urologie, Nürtingen; Arnulf Stenzl, University Hospital, Tübingen, Germany; Fred Saad, Centre Hospitalier de I'Université de Montréal, Montreal, Quebec, Canada; Elaine Lam, University of Colorado Anschutz Medical Campus, Aurora, CO; Jonathan Polikoff, Kaiser Permanente Medical Group, San Diego; David Ramies, Colin Hessel, and Aaron Weitzman, Exelixis, South San Francisco, CA; and Paul Mainwaring, Hematology and Oncology Clinics of Australia, Brisbane, Queensland, Australia. 


\section{AUTHORS' DISCLOSURES OF POTENTIAL CONFLICTS OF INTEREST}

Phase III Study of Cabozantinib in Previously Treated Metastatic Castration-Resistant Prostate Cancer: COMET-1

The following represents disclosure information provided by authors of this manuscript. All relationships are considered compensated. Relationships are self-held unless noted. I = Immediate Family Member, Inst = My Institution. Relationships may not relate to the subject matter of this manuscript. For more information about ASCO's conflict of interest policy, please refer to www.asco.org/rwc or jco.ascopubs.org/site/ifc.

Matthew Smith

Consulting or Advisory Role: Exelixis

Johann De Bono

No relationship to disclose

Cora Sternberg

Honoraria: Astellas, Bayer HealthCare Pharmaceuticals, Janssen, Sanofi Research Funding: Exelixis

Sylvestre Le Moulec

No relationship to disclose

\section{Stéphane Oudard}

Honoraria: Sanofi, Bayer HealthCare Pharmaceuticals, Astellas Pharma, Janssen, Ipsen

Consulting or Advisory Role: Sanofi, Bayer HealthCare Pharmaceuticals, Astellas Pharma, Janssen Oncology, Ipsen

\section{Ugo De Giorgi}

Consulting or Advisory Role: Astellas Pharma, Sanofi

Michael Krainer

Consulting or Advisory Role: Medivation, Astellas Pharma, AstraZeneca, MorphoSys

\section{Andries Bergman}

Consulting or Advisory Role: Astellas Pharma, Sanofi, Bayer HealthCare Pharmaceuticals, Amgen, Janssen

Research Funding: Amgen, Astellas Pharma, Bayer HealthCare

Pharmaceuticals

Travel, Accommodations, Expenses: Amgen, Astellas Pharma, Bayer HealthCare Pharmaceuticals, Sanofi

\section{Wolfgang Hoelzer}

Research Funding: Exelixis

Ronald De Wit

Honoraria: Sanofi, Astellas Pharma, Millennium Pharmaceuticals Consulting or Advisory Role: Sanofi, Astellas Pharma, Millennium Pharmaceuticals

Research Funding: Sanofi (Inst), Astellas Pharma (Inst), Janssen (Inst)

\section{Martin Bögemann}

Honoraria: Janssen-Cilag, Astellas Pharma, Novartis, Amgen, Bayer HealthCare Pharmaceuticals

Consulting or Advisory Role: sanofi-aventis, Bayer HealthCare

Pharmaceuticals, Amgen, Janssen-Cilag

Research Funding: Exelixis (Inst)

Travel, Accommodations, Expenses: Bayer HealthCare Pharmaceuticals, Janssen-Cilag, sanofi-aventis, Astellas Pharma

\section{Fred Saad}

Honoraria: Astellas Pharma, Janssen, Sanofi, Bayer HealthCare

Pharmaceuticals, Amgen

Consulting or Advisory Role: Astellas Pharma, Janssen, Sanofi, Bayer

HealthCare Pharmaceuticals, Amgen

Giorgio Cruciani

No relationship to disclose

\section{Antoine Thiery-Vuillemin}

Employment: AstraZeneca

Honoraria: Novartis, Pfizer, Ipsen, Takeda Pharmaceuticals, Roche

Consulting or Advisory Role: Novartis, Pfizer, Exelixis, Ferring

Pharmaceuticals

Research Funding: Exelixis (Inst)

Travel, Accommodations, Expenses: Novartis, AstraZeneca, Pfizer, Roche, Ipsen, Takeda Pharmaceuticals

\section{Susan Feyerabend}

No relationship to disclose

\section{Kurt Miller}

Honoraria: Astellas Pharma, Janssen, AstraZeneca, Bristol-Myers Squibb, Ferring Pharmaceuticals, Novartis, Merck Sharp \& Dohme, Roche, Sotio Consulting or Advisory Role: Astellas Pharma, Janssen, AstraZeneca, Bristol-Myers Squibb, Ferring Pharmaceuticals, Novartis, Merck Sharp \& Dohme, Roche, Sotio

Speakers' Bureau: Janssen, Novartis

Travel, Accommodations, Expenses: Janssen, Roche

\section{Nadine Houédé}

No relationship to disclose

\section{Syed Hussain}

Consulting or Advisory Role: Pierre Fabre, Astellas Pharma, Bayer HealthCare Pharmaceuticals

Research Funding: Boehringer Ingelheim, Janssen-Cilag, Pierre Fabre Travel, Accommodations, Expenses: Janssen-Cilag, Bayer HealthCare Pharmaceuticals, Boehringer Ingelheim, Pierre Fabre, Astellas Pharma, Pfizer, Roche, Merck Sharp \& Dohme Oncology

\section{Elaine Lam}

Consulting or Advisory Role: Exelixis, Bristol-Myers Squibb Research Funding: Exelixis (Inst), Janssen (Inst), Astellas Pharma (Inst), Bristol-Myers Squibb (Inst), Roche (Inst), Genentech (Inst), Argos Therapeutics (Inst)

\section{Jonathan Polikoff}

No relationship to disclose

\section{Arnulf Stenzl}

Honoraria: Ipsen, Janssen, Alere, Novartis

Consulting or Advisory Role: Ipsen, Janssen, Alere, Novartis Speakers' Bureau: Janssen, Ipsen

Research Funding: Johnson \& Johnson (Inst), Amgen (Inst), Bayer HealthCare Pharmaceuticals (Inst), CureVac (Inst), Immatics (Inst), Novartis (Inst), Karl Storz (Inst), Photocure (Inst)

\section{Paul Mainwaring}

Honoraria: Roche, Novartis, Astellas Pharma, Janssen

Consulting or Advisory Role: Astellas Pharma, Janssen, Novartis Speakers' Bureau: Novartis, Pfizer, Astellas Pharma, Janssen Research Funding: Roche (Inst), Novartis (Inst), Janssen (Inst), Astellas Pharma (Inst), Exelixis (Inst)

Patents, Royalties, Other Intellectual Property: Xing Technologies Travel, Accommodations, Expenses: Novartis, Pfizer, Janssen, Astellas Pharma, Roche 
David Ramies

Employment: Exelixis

Stock or Other Ownership: Exelixis

Colin Hessel

Employment: Exelixis

Stock or Other Ownership: Exelixis
Aaron Weitzman

Employment: Exelixis

Stock or Other Ownership: Exelixis, Kite Pharma, Juno Therapeutics,

Calithera Biosciences

Consulting or Advisory Role: Agios, Principia, Immune Pharmaceuticals

Karim Fizazi

No relationship to disclose 


\section{Acknowledgment}

Medical writing and editorial support was provided by Tricia Newell and Mark English (Bellbird Medical Communications) and Dana T. Aftab (Exelixis).

\section{Appendix}

\section{Exc/usion Criteria}

Exclusion criteria included receipt of any anticancer agent apart from agents to maintain castration status within 2 weeks before random assignment, radiation therapy within 4 weeks or radionuclide therapy within 6 weeks of random assignment, and known brain metastases or cranial epidural disease.

\section{Random Assignment and Blinding}

Random assignment was conducted using an interactive voice record system or interactive Web record system. Treatment assignment was not known to patients, investigators, study centers, the sponsor, or any study-affiliated personnel other than those authorized to access treatment assignment for regulatory safety reporting and submission processes, interactive voice record system or interactive Web record system administration, or drug supply management. Cabozantinib-matched placebo was packaged and color-, size-, and shape-matched to be indistinguishable from cabozantinib. Prednisone tablets were commercially obtained and overencapsulated in hard gelatin capsule shells to blind product identity. Prednisone-matched placebo capsules were color- and size-matched to the overencapsulated prednisone.

\section{Dose Reductions and Modifications}

Dose reduction or interruption was recommended for intolerable grade 2 toxicities that could not be adequately managed or for grade 3 toxicities apart from clinically nonrelevant laboratory abnormalities. A patient experiencing grade 4 toxicities apart from clinically nonrelevant laboratory abnormalities was to have immediate interruption of dosing and to be permanently discontinued from the trial unless the patient was deriving clear clinical benefit from therapy as determined by the investigator or if the toxicity could be managed with a dose reduction after recovery to grade 1 or less and optimal medical care. Dose modifications or interruptions may have occurred with a lower-grade toxicity if it was in the interest of patient safety.

\section{Bone Scan Response}

Whole-body anterior and posterior bone scans were acquired on all patients approximately 3 hours ( \pm 15 minutes) after intravenous administration of $25 \mathrm{mCi}( \pm 10 \%)$ of a technetium-99 bone-seeking radiopharmaceutical. The same tracer, tracer dose, and delay from injection to scanning were used for an individual patient across the study. Computed tomography scans included full coverage of the chest, abdomen, and pelvis at screening and every 12 weeks after random assignment. If a magnetic resonance imaging scan was performed for the abdominal and pelvic examinations, a noncontrast computed tomography chest scan was also performed. The same modality and imaging protocol used at baseline were to be used at all subsequent imaging time points. All study images acquired both on and off schedule were provided by the study site to the independent review committee (IRC) for independent evaluation. Site-specific image acquisition guidelines were provided separately by the IRC. In addition, available clinical information that could have influenced the interpretation of radiographic images was to be documented at the time of tumor assessments. Each scan analysis was read and confirmed visually by two independent core board-certified nuclear medicine physicians or radiologists, using quantitative computer-aided detection software, adjudicated by a third blinded nuclear medicine physician if the two primary readers disagreed on key parameters.

A response of unevaluable was assigned if bone scan results could not be interpreted because of inconsistent image acquisition parameters compared with the reference scan, incomplete imaging, or other technical deficiencies. Stable disease was defined as not meeting the criteria for response, progressive disease, or unable to evaluate.

\section{Assessment of Circulating Tumor Cells and Bone Biomarkers}

Serial blood samples were collected for enumerations of circulating tumor cells (CTCs) and bone biomarkers bonespecific alkaline phosphatase (BSAP) and $\mathrm{N}$-terminal and C-terminal cross-linked telopeptides of type I collagen at baseline and at the end of weeks 6 and 12. Patients were partitioned into the following CTC categories at baseline: fewer than five CTCs per $7.5 \mathrm{~mL}$ of blood versus five or more. CTCs per $7.5 \mathrm{~mL}$ of blood. Patients with five or more CTCs at baseline were assessed for conversion to fewer than five CTCs at weeks 6 and/or 12, and patients with fewer than five CTCs at baseline were assessed for conversion to five or more CTCs at weeks 6 and/or 12. For bone biomarkers (BSAP and N-terminal and C-terminal 
cross-linked telopeptides of type I collagen), patients were assessed for best change (greatest decrease or lowest increase) at weeks 6 and/or 12 .

\section{Assessment of Skeletal-Related Events}

Symptomatic skeletal events (SSEs) were defined as any one of the following: radiation therapy to bone including the use of bone-targeted radiopharmaceuticals, pathologic fracture, spinal cord compression, or bone surgery. Any SSEs occurring in the previous 12 months or within a longer timeframe but that were considered clinically significant were recorded at baseline. For postbaseline assessments, the investigator determined whether an SSE had occurred, and a description of the event was recorded.

\section{Assessment of Overall Survival}

Duration of overall survival was defined as the time from random assignment to death resulting from any cause. For patients who were alive at the time of data cutoff or who were permanently lost to follow-up, duration of overall survival was right-censored at the earlier of the data cutoff date or the date the patient was last known to be alive.

\section{Subgroup Analyses}

Prespecified subgroup analyses for both the primary and secondary end points evaluated the influence of baseline and demographic characteristics on outcome, including region (North America, Europe, or Australia), prior cabazitaxel therapy (yes $v$ no), visceral metastases (yes $v$ no), baseline Brief Pain Inventory item $3(<4 v \geq 4)$, Eastern Cooperative Oncology Group performance status ( 0 to $1 v 2$ ), lactate dehydrogenase ( $\leq$ upper limit of normal [ULN] $v>$ ULN), prednisone use (yes $v$ no), bone scan lesion area ( $<$ median $v \geq$ median), BSAP ( $\leq$ ULN $v>$ ULN), CTCs $(<v, \geq 5$ ), and prostate-specific antigen (PSA) $(<$ median $v \geq$ median).

\section{Assessment of Secondary End Point}

For the secondary analysis of the proportion of patients experiencing a bone scan response (BSR) according to IRC assessment at the end of week 12, a stratified two-sided Cochran-Mantel-Haenszel test at the .05 level of significance was used to compare the two treatment groups, using the same stratification factors as those used for the random assignment schedule. A gatekeeping strategy for analysis of the secondary efficacy end point controlled the family-wise error rate at 0.05 .

\section{Assessment of Exploratory End Points}

Each exploratory end point was analyzed using an appropriate two-sided statistical test without adjustment for multiplicity. Exploratory analyses of BSR included best BSR at any time point and duration of BSR. The hazard ratio was estimated using a Cox regression model with treatment arm as the only main effect and stratifying by the same stratification factors used for random assignment. Descriptive statistics were performed for CTC conversion, and categorical analyses were also performed. The median time to first SSE and the associated 95\% CI for each treatment arm were estimated using the Kaplan-Meier method.

\section{PSA Responses}

Blood samples for PSA analysis were collected at screening, the end of week 12 after the date of random assignment, and every 12 weeks thereafter and assessed at a central laboratory.

\section{Causes of Death Through 30 Days of Last Dose of Study Drug}

The most common causes of death (occurring in $\geq$ two patients in either treatment arm) through 30 days of the last dose of study drug were prostate cancer (cabozantinib, $n=50$; prednisone, $n=26$ ), general physical health deterioration $(n=14 ; n=1)$, death not otherwise specified $(n=4 ; n=1)$, sepsis $(n=3 ; n=1)$, euthanasia $(n=3 ; n=0)$, pulmonary embolism $(n=3 ; n=0)$, multiorgan failure $(n=2 ; n=2)$, pneumonia $(n=2 ; n=1)$, renal failure $(n=2 ; n=1)$, septic shock $(n=2 ; n=1)$, respiratory failure $(\mathrm{n}=2 ; \mathrm{n}=0)$, cardiac failure $(\mathrm{n}=1 ; \mathrm{n}=1)$, and sudden death $(\mathrm{n}=1 ; \mathrm{n}=1)$. 
Table A1. SSES

\begin{tabular}{lcc}
\hline \multicolumn{1}{c}{ SSE } & & No. (\%) \\
\cline { 2 - 3 } & $\begin{array}{c}\text { Cabozantinib } \\
(\mathrm{n}=682)\end{array}$ & $\begin{array}{c}\text { Prednisone } \\
\text { (n = 346) }\end{array}$ \\
\hline Patient incidence of any post-random assignment SSE & $98(14)$ & $71(21)$ \\
Radiation therapy to bone & $81(12)$ & $63(18)$ \\
Spinal cord compression & $19(3)$ & $15(4)$ \\
Pathologic fractures & $12(2)$ & $7(2)$ \\
Surgery to bone & $9(1)$ & 7 (2) \\
\hline
\end{tabular}

NOTE. Bone-targeted therapies consist of bisphosphonates or denosumab. Treatment-emergent SSEs recorded from the adverse event case report form page categories are not mutually exclusive. For the determination of patient incidence, only the first event per patient was counted. The denominator includes the shortest of the following durations: time from first dose to an event, time from first dose to data cutoff, or time from first dose until 30 days after last dose.

Abbreviation: SSE, symptomatic skeletal event.

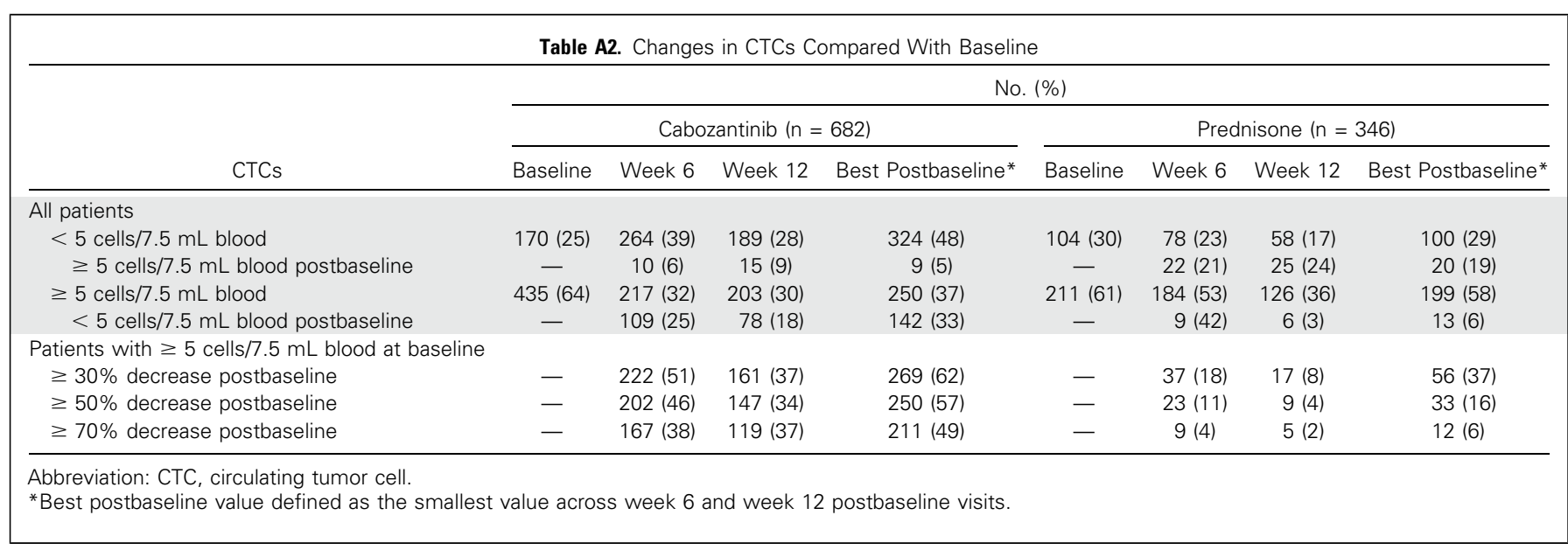

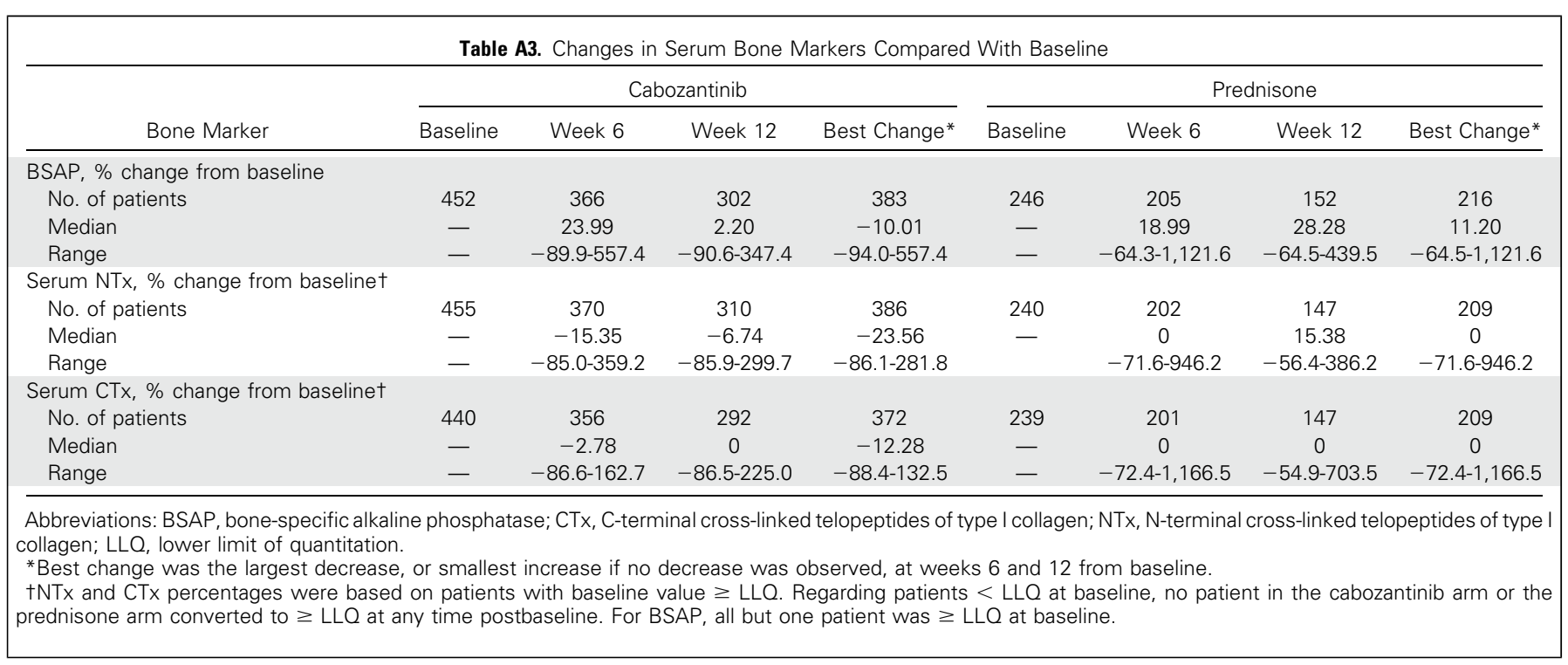


Table A4. AEs Leading to Study Drug Discontinuation in $\geq 1 \%$ of Patients in Either Treatment Arm Regardless of Relationship to Disease Progression

\begin{tabular}{|c|c|c|}
\hline \multirow[b]{2}{*}{$A E$} & \multicolumn{2}{|c|}{ No. (\%) } \\
\hline & $\begin{array}{l}\text { Cabozantinib } \\
(n=681)\end{array}$ & $\begin{array}{l}\text { Prednisone } \\
(\mathrm{n}=342)\end{array}$ \\
\hline Fatigue & $54(7.9)$ & $14(4.1)$ \\
\hline General physical health deterioration & $50(7.3)$ & $17(5.0)$ \\
\hline Asthenia & $34(5.0)$ & $6(1.8)$ \\
\hline Nausea & $29(4.3)$ & $8(2.3)$ \\
\hline Decreased appetite & $28(4.1)$ & $10(2.9)$ \\
\hline Diarrhea & $20(2.9)$ & $2(0.6)$ \\
\hline Vomiting & $18(2.6)$ & $3(0.9)$ \\
\hline Pulmonary embolism & $17(2.5)$ & $1(0.3)$ \\
\hline $\begin{array}{l}\text { Palmar-plantar erythrodysaesthesia } \\
\text { syndrome }\end{array}$ & $15(2.2)$ & 0 \\
\hline Prostate cancer & $14(2.1)$ & $9(2.6)$ \\
\hline Anemia & $12(1.8)$ & $7(2.0)$ \\
\hline Weight decreased & $11(1.6)$ & $4(1.2)$ \\
\hline Dehydration & $11(1.6)$ & 0 \\
\hline Bone pain & $10(1.5)$ & $16(4.7)$ \\
\hline Back pain & $8(1.2)$ & $11(3.2)$ \\
\hline Stomatitis & $8(1.2)$ & 0 \\
\hline Metastatic pain & $7(1.0)$ & $4(1.2)$ \\
\hline Spinal cord compression & $7(1.0)$ & $4(1.2)$ \\
\hline Arthralgia & $7(1.0)$ & $2(0.6)$ \\
\hline Dyspnea & $7(1.0)$ & $2(0.6)$ \\
\hline Pain & $5(0.7)$ & $4(1.2)$ \\
\hline Thrombocytopenia & $5(0.7)$ & $4(1.2)$ \\
\hline Pyrexia & $4(0.6)$ & $4(1.2)$ \\
\hline Aspartate aminotransferase increased & $2(0.3)$ & $4(1.2)$ \\
\hline Musculoskeletal pain & $1(0.1)$ & $4(1.2)$ \\
\hline
\end{tabular}

Abbreviation: $A E$, adverse event.

Table A5. AEs Leading to Dose Modification in $\geq 5 \%$ of Patients in Either Treatment Arm

\begin{tabular}{|c|c|c|}
\hline \multirow[b]{2}{*}{$A E$} & \multicolumn{2}{|c|}{ No. (\%) } \\
\hline & $\begin{array}{l}\text { Cabozantinib } \\
(n=681)\end{array}$ & $\begin{array}{c}\text { Prednisone } \\
(n=342)\end{array}$ \\
\hline No. of patients with $\geq$ one $A E$ leading to dose modification & $600(88)$ & $154(45)$ \\
\hline Decreased appetite & $144(21)$ & $14(4.1)$ \\
\hline Diarrhea & $144(21)$ & $8(2.3)$ \\
\hline Fatigue & $141(21)$ & $21(6.1)$ \\
\hline Nausea & $135(20)$ & $12(3.5)$ \\
\hline Asthenia & $122(18)$ & $11(3.2)$ \\
\hline Palmar-plantar erythrodyaesthesia syndrome & $104(15)$ & 0 \\
\hline Vomiting & $103(15)$ & $12(3.5)$ \\
\hline Hypertension & $73(11)$ & $2(0.6)$ \\
\hline Mucosal inflammation & $52(7.6)$ & 0 \\
\hline Weight decreased & $49(7.2)$ & $4(1.2)$ \\
\hline Stomatitis & $45(6.6)$ & 0 \\
\hline General physical health deterioration & $34(5.0)$ & $10(2.9)$ \\
\hline
\end{tabular}

Abbreviation: $A E$, adverse event. 


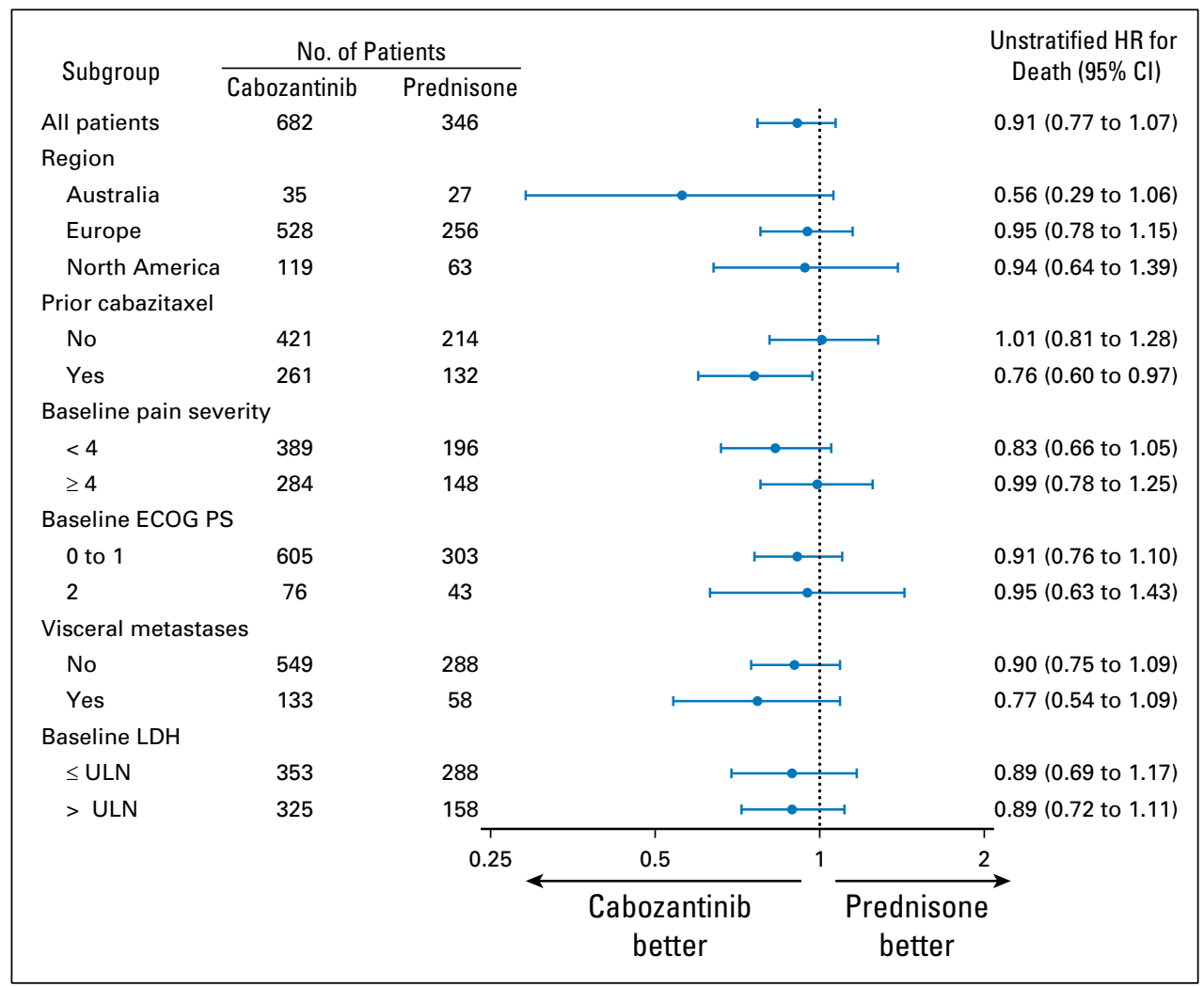

Fig A1. Forest plot of overall survival by subgroup categories. ECOG PS, Eastern Cooperative Oncology Group performance status; HR, hazard ratio; LDH, lactate dehydrogenase; ULN, upper limit of normal. 